\title{
Cost Estimation and Efficiency Analysis of Korean CANDU Spent Fuel Disposal Alternatives in Consideration of Future Price Volatility
}

\author{
Sungsig Bang, ${ }^{1}$ Yanghon Chung, ${ }^{1}$ Dongphil Chun, ${ }^{2}$ Chulhong Kwon, ${ }^{3}$ and Sungjun Hong ${ }^{3}$ \\ ${ }^{1}$ Department of Business and Technology Management, Korea Advanced Institute of Science and Technology, 291 Daehak-ro, \\ Yuseong-gu, Daejeon 34141, Republic of Korea \\ ${ }^{2}$ Graduate School of Management of Technology, Pukyong National University, 365 Sinseon-ro, Nam-gu, \\ Busan 48547, Republic of Korea \\ ${ }^{3}$ Korea Institute of Energy Research, 152 Gajeong-ro, Yuseong-gu, Daejeon 34129, Republic of Korea \\ Correspondence should be addressed to Sungsig Bang; ssbang@kaist.ac.kr
}

Received 10 July 2016; Revised 4 October 2016; Accepted 23 November 2016

Academic Editor: Eugenijus Ušpuras

Copyright (C) 2016 Sungsig Bang et al. This is an open access article distributed under the Creative Commons Attribution License, which permits unrestricted use, distribution, and reproduction in any medium, provided the original work is properly cited.

In Korea, spent fuel is temporarily stored in spent fuel pools at nuclear reactor sites and it is predicted to become saturated between 2020 and 2024. For this reason, four disposal alternatives (KRS-1, A-KRS-1, A-KRS-21, and A-KRS-22) have been developed in order to carry out the direct disposal of the CANDU spent fuel. The objective of this study is to conduct cost efficiency analysis of the disposal alternatives in consideration of price volatility for the radioactive waste repository. To derive future price volatility, this study used the ARIMA model. As a result, A-KRS-1 is the most efficient in terms of price per bundle using 2015 price. As for the results using ARIMA model, except in the case of KRS-1, the cost per bundle of A-KRS-1, A-KRS-21, and A-KRS-22 is decreased. Cost estimation using ARIMA model shows little change or decreases in cost while cost estimation using inflation rates for 2020 resulted in approximately $7.2 \%$ increases compared to 2015 for all options. As for the results of scenario analysis, A-KRS-1 earned 8,160 points, while A-KRS-22 followed closely behind with 7,980 points among the total 24,300 points. The results of this study provide invaluable policy data for any nation considering the construction of spent nuclear fuel repository.

\section{Introduction}

Spent fuel is temporarily stored in spent fuel pools at nuclear reactor sites in Korea. As of the end of 2015, the spent fuel amounts about 14,000 tons in Korea. Assuming that the annual production of spent fuel is about 650 tons, the storage facilities will soon fill up to their maximum [1-3].

Currently, CANDU (CANada Deuterium Uranium) reactors at Wolseong Nuclear Power Plant Units 1, 2, 3, and 4 are in operation. Among 650 tons of spent nuclear fuel, around 300 tons of the annual production is spent nuclear fuel from CANDU reactors [1-3]. As of the end of 2015, the storage facility capacity of the Wolseong Nuclear Power Plant was 499,632 bundles (9,204 tons) and the actual stored amount was 408,796 bundles (7,531 tons), and it is predicted to become saturated between 2020 and 2024 [2-4].
As natural uranium is used rather than enriched uranium for CANDU reactors, the economic usefulness obtained through reprocessing is small, and thus direct disposal is considered [5]. Due to these results, Korea is expected to face serious problems if there are no additional storage facilities. Accordingly, the government is devising mid- to long-term measures, including site selection, for the construction of storage facilities [1].

For this reason, in Korea, four disposal alternatives have been developed in order to carry out the direct disposal of the CANDU spent fuel [6]. Disposal alternatives developed since 1997 are now at a state in which A-KRS-22 concept was developed after starting from the KRS (Korea Reference System) [6].

Studies on spent nuclear fuel repository construction in Korea were conducted by Cho et al. [7], Kim and Choi [8], and 
TABLE 1: The features of disposal alternatives.

\begin{tabular}{|c|c|c|c|c|}
\hline & KRS-1 & A-KRS-1 & A-KRS-21 & A-KRS-22 \\
\hline Disposal tunnel & \multicolumn{4}{|c|}{$500 \mathrm{~m}$ below the ground to the granite } \\
\hline Disposal hole & $4 \mathrm{r}$ & & & $5 \mathrm{~m}$ \\
\hline \multirow{2}{*}{ Canister } & Copper plate $5 \mathrm{~cm}$ & & Copper pow & \\
\hline & \multicolumn{2}{|c|}{ One disposal canister in one disposal hole } & \multicolumn{2}{|c|}{ Two disposal canisters in one disposal hole } \\
\hline Bentonite & One-layered bentonite $50 \mathrm{~cm}$ & One-layere & ite $40 \mathrm{~cm}$ & Double-layered bentonite $20 \mathrm{~cm}$ \\
\hline Backfilling & \multicolumn{4}{|c|}{ Bentonite $30 \%$} \\
\hline
\end{tabular}

Lee et al. $[9,10]$. However, economic analysis of repository construction alternatives is lacking. The research by Kim et al. [6] performed a comparative analysis of cost efficiency with respect to the costs of 2011 for 4 alternatives developed in Korea.

In Korea, a future cost of nuclear facilities is calculated taking into account the inflation rate in accordance with the regulations for radioactive waste (Notification number 2015-132. Regulations for calculating radioactive waste management costs and spent fuel management charges [11]). Therefore, the future cost constantly increases every year due to the inflation rate, and because its increase takes an exponential form, the cost increases sharply as time passes.

However, there is a possibility that the future price will not increase as constantly as the inflation rate. Furthermore, expenses for the distant future, if calculated using the existing calculation method accounting for the inflation rate, might increase by geometrical progression. Therefore, future cost volatility is a significant problem given that the actual construction of a repository will take place in the future.

Against this backdrop, this study aims to predict the volatility of the future cost using a statistical method based on actual legacy data and compare that prediction with predictions made using the current method that employs the inflation rate. Additionally, this study created various scenarios using the forecasted data to perform a comparative analysis of the cost efficiency for each alternative.

The remainder of this paper is organized as follows. In Section 2, we summarize the research models and the methodologies. The estimated results are presented in Section 3. Section 4 contains conclusions and implications of this study.

\section{Cost Estimation Methods}

2.1. The Repository for Spent Fuel. Korea has developed four disposal alternatives to this day in order to carry out the direct disposal of the CANDU spent fuel [6]. Disposal alternatives developed since 1997 are now at a state in which A-KRS-22 concept was developed after starting from the KRS (Korea Reference System) [6].

When the dominant characteristics of each alternative are examined, KRS-1 is based on the concept in which spent fuel is vertically emplaced to the granite located $500 \mathrm{~m}$ below the ground level $[6,12]$. A-KRS-21 and A-KRS-22 decreased the height of the disposal canister in order to emplace two

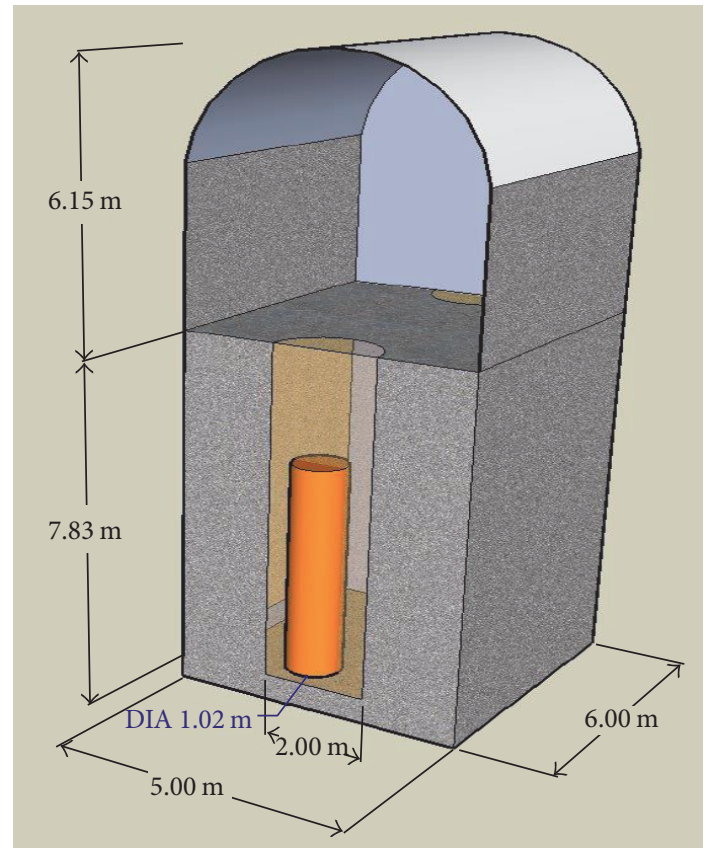

Figure 1: Concept of unit module [6].

disposal canisters in one disposal hole using the vertical emplacement [6].

To this end, in A-KRS-21 and A-KRS-22, the scenarios used in this study, the disposal hole spacing was widened, and bentonite, a buffer material, was used in two layers, each $20 \mathrm{~cm}$ thick, instead of using one layer of $50 \mathrm{~cm}$ thickness.

Table 1 and Figure 1 show the features of each disposal alternative and concept of unit module.

\subsection{The Research Methodologies of Cost Estimation and Anal-} ysis for Disposal Alternatives. Although absorption costing is typically used in cost efficiency calculations, we chose to use dominant cost driver analysis [4, 13-15]. Dominant cost driver analysis was chosen above absorption costing for three reasons. Firstly, dominant cost driver analysis takes less time and is less costly. Secondly, apart from the dominant cost drivers, other cost drivers have very little influence on the cost. Thirdly, since this was not an actual constructed facility, we resorted to a concept design and were not able to determine every cost driver in action. Because of this constraint, no cost drivers other than the major ones were 
TABLE 2: The conditions of disposal alternatives.

\begin{tabular}{|c|c|c|c|c|c|}
\hline & KRS-1 & A-KRS-1 & A-KRS-21 & A-KRS-22 & \\
\hline Capacity (bundles) & 297 & 420 & 240 & 240 & \\
\hline Distance of disposal tunnel [m] & 40 & 40 & 40 & 40 & \\
\hline Disposal hole size $[\mathrm{cm}]$ & D $224 \times$ H 783 & D $225 \times$ H 663 & D $208 \times$ H 799 & D $208 \times$ H 799 & \\
\hline Pitch of disposal hole $[\mathrm{m}]$ & 4 & 4 & 5 & 5 & \\
\hline Bentonite thickness $[\mathrm{cm}]$ & 50 & 40 & 40 & 20 (Sand $30 \%)$ & 20 \\
\hline Canister size $[\mathrm{cm}]$ & D $102 \times$ H 483 & D $124.4 \times$ H 412.9 & D $128 \times$ H 274.5 & D $128 \times$ H 274.5 & \\
\hline Backfilling volume of unit module $\left[\mathrm{m}^{3}\right]$ & 114.76 & 114.76 & 71 & 71 & \\
\hline
\end{tabular}

identified and other cost drivers have little or no impact on the ranking of the options.

In the use of dominant cost driver analysis, the key is to accurately deduce the dominant cost drivers. In this study, the five dominant cost drivers such as tunnel excavation (excavation cost of disposal tunnel), disposal hole (excavation cost of disposal borehole), bentonite (bentonite buffer cost of borehole), canister (material cost of disposal canister), and backfilling (backfilling bentonite cost of disposal tunnel) were conducted [6].

The canister is composed of two parts: an inner canister, which is made of cast iron, and an outer canister, which is made of copper [16]. CANDU spent fuel is stored in a cylindrical canister made of cast iron. Afterwards, the surface of the cylindrical cast iron canister is surrounded with copper in order to prevent corrosion. This copper structure is made of a copper plate measuring $5 \mathrm{~cm}$ in the case of KRS-1 and copper powder measuring $1 \mathrm{~cm}$ in the case of other alternatives (A-KRS-1, A-KRS-21, and A-KRS-22), respectively [6]. This is expressed as

$$
\mathrm{UC}_{i, t}=\frac{C_{\mathrm{et}, t}+C_{\mathrm{eh}, t}+C_{\mathrm{bc}, t}+C_{\mathrm{cc}, t}+C_{\mathrm{bf}, t}}{N_{b, t}},
$$

where $\mathrm{UC}_{i, t}$ is the unit cost per bundles of alternative $i$ at $t$ year, $N_{b, t}$ is the number of bundles in unit module at $t$ year, $C_{\text {et, } t}$ is excavation cost of disposal tunnel in unit module at $t$ year, $C_{\mathrm{eh}, t}$ is excavation cost of disposal borehole in unit module at $t$ year, $C_{\mathrm{bb}, t}$ is bentonite buffer cost of disposal borehole in unit module at $t$ year, $C_{c c, t}$ is material cost of disposal canister (cast iron cost + copper cost) in unit module at $t$ year, and $C_{\mathrm{bf}, t}$ is backfilling cost in unit module at $t$ year.

The unit used in disposal efficiency calculation is bundled as the amount of spent fuel bundles, which can be stored in a single canister, differs between each option. Therefore, the cost efficiency of the various options can only be compared when calculated per bundle.

There are 5 dominant cost drivers for repositories as comparing the cost efficiency of the options requires a comparison of costs incurred at underground repositories. The comparison of costs by dominant cost drivers allows us to understand the costs incurred in the respective categories for each disposal option and deduce the cost driver with the greatest economic value in each option. The conditions for each disposal option in cost calculations are outlined in Table 2.
2.3. The Inflation Rate Model for Cost Estimation. In the nuclear cost estimation, the inflation rate announced by the Ministry of Trade, Industry and Energy is used to estimate the future cost and, currently, the $1.40 \%$ inflation rate is applied [11].

The future cost is drawn by multiplying the current prime cost by the inflation rate. Inevitably, the future cost is always assumed to be higher than the current cost, and its increase is made in an exponential form rather than as an additive term.

The price model considering the inflation rate can be described as

$$
\mathrm{UMC}_{i, t}=\mathrm{UMC}_{i, t_{0}}(1+r)^{t-t_{0}},
$$

where $\mathrm{UMC}_{i, t}$ is unit module cost using of alternative $i$ using the inflation rate at $t$ year, $\mathrm{UMC}_{i, t_{0}}$ is unit module cost using of alternative $i$ at based year (based year $=2015$ ), and $r$ is the inflation rate $(1.40 \%)$.

2.4. ARIMA Model for Price Forecasting and Volatility. ARIMA (Autoregressive Integrated Moving Average) is the model that is most widely used for a forecasting model using time series.

ARIMA model consists of the following three parts: $\operatorname{AR}(p), I(d)$, and $\operatorname{MA}(q)$. It is represented by ARIMA $(p, d, q)$, where $p$ the autoregressive parameter, $d$ is integrated parameter, and $q$ is the moving average parameter. White noise in the ARIMA model refers to the error. The errors are as follows. First, the average is close to 0 , second, distribution is a random variable with normal distribution, and, third, it is assumed that they are independent of each other. Detailed description of the ARIMA model is as follows [17-20].

The AR model, an autoregressive model, assumes that the variable of time $t$ is affected by the times $t-1$ to $t-p$ :

$$
y_{t}=\mu+\gamma_{1} y_{t-1}+\gamma_{2} y_{t-2}+\cdots+\gamma_{p} y_{t-p}+\varepsilon_{t} .
$$

Hence, when $\mu$ is the white noise and $y_{t}$ is affected by the times $t-1$ to $t-p$, then the following can result. When $p=1$ in actuality, the AR (1) model can be described in the following manner:

$$
y_{t}=\mu+\gamma_{1} y_{t-1}+\varepsilon_{t} .
$$

The MA model, a moving average model, uses white noise to derive the fluctuation at time $t$. In other words, when the white noise at time $t$ is assumed to be $\mu$, the following 
descriptions can be made if $y_{t}$ is affected by the times $t-1$ to $t-q$ :

$$
y_{t}=\mu-\theta_{1} \varepsilon_{t-1}-\theta_{2} \varepsilon_{t-2}-\cdots-\theta_{q} \varepsilon_{t-q}+\varepsilon_{t} .
$$

The MA (1) model can be described in the following manner:

$$
y_{t}=\mu-\theta_{1} \varepsilon_{t-1}+\varepsilon_{t}
$$

As described above, the ARMA model is a combination of the AR model, which uses the descriptive variables of the past time series data, and the MA model, which uses the descriptive variables of the past error terms. Also, this is the same as the ARIMA $(1,0,1)$ model. The ARMA model is an analysis model for stationary time series data. Here, the ARIMA model is a model with an Integrated concept in order to use nonstationary time series data. Therefore, the ARIMA model not only considers the stationary time series model but also the nonstationary time series model. This Integrated $(I=1)$ can be described in the following manner:

$$
\Delta y_{t}=y_{t}-y_{t-1}
$$

Finally, ARIMA model can be described as

$$
\begin{aligned}
\Delta^{d} y_{t}= & \mu+\gamma_{1} \Delta^{d} y_{t-1}+\cdots+\gamma_{p} \Delta^{d} y_{t-p}+\varepsilon_{t}-\theta_{1} \varepsilon_{t-1} \\
& -\cdots-\theta_{q} \varepsilon_{t-q} .
\end{aligned}
$$

To derive future price volatility, this study used the ARIMA method developed by Box and Jenkins [17].

For the model estimation, the Box-Jenkins estimation method was used [17], where the autocorrelation and partial correlation of the data were first analyzed to estimate a number of models, a comparative analysis of the estimated model coefficients was conducted, and, lastly, the conformity of the final estimation model was investigated.

2.5. Scenario Analysis Using the ARIMA Model. The base year of data collection in this study is the end of 2015 year.

However, future cost volatility is a significant problem given that the actual construction of a repository will take place in the future. Accordingly, this study used real past data to forecast the future cost volatility and created various scenarios using the forecasted data to perform a comparative analysis of the cost efficiency for each alternative.

In this study, such volatility possibility was derived using the ARIMA method and the statistical method of confidence intervals. The confidence intervals used in this study refer to the probability that the range of fluctuation in the future is within the confidence interval after analyzing the actual data.

This study uses $68 \%$ confidence intervals as the risk of fluctuation. The value of $68 \%$ was selected for confidence intervals as high confidence intervals would result in high variation, possibly yielding results that are not meaningful:

$$
\mathrm{FP}-1 \frac{\sigma}{\sqrt{n}}<\mathrm{FP}<\mathrm{FP}+1 \frac{\sigma}{\sqrt{n}}
$$

where FP is forecasted price, $\sigma$ is standard deviation, and $n$ is sample size.

In setting the forecasting period, it was taken into account the fact that discussions on the construction of permanent disposal sites are likely to take place from now on because the storage facilities will soon fill up to their maximum capacity after 2020. Since intermediate storage facilities belong to the stage before permanent disposal and are not intended for permanent storage, additional facilities are needed within 5 years, at the latest. Using data up to 2015, this study performed cost efficiency analysis with consideration of price volatility for five years into the future, corresponding to 2020 .

In this procedure, the configuration of the scenarios was as follows. First, analysis of the following 5 costs was conducted: disposal tunnel and hole, bentonite and backfilling, cast iron, copper plate, and copper powder. The cost drivers of these 5 elements will have 3 types of cost volatility values including the forecasting value through ARIMA analysis, UCL (Upper Confidence Limit) value, and LCL (Lower Confidence Limit) value. Also, 243 or 3 to the 5 th power number of scenarios will exist.

2.6. Data Collection. In this study, 16 years' worth of data was collected from 2000 to 2015 to forecast price volatility. Based on Finnish unit price for 2010, Korea's average increase/decrease in wages for the nuclear industry was substituted to calculate the excavation price for disposal tunnel and disposal holes [21]. Other unit prices were obtained by using The Information on Commodity Prices from KPRC (Korea Price Research Center, Corp.) [22] and Price Information of Korea from KPI (Korea Price Information, Corp.) [23]. The pricing data of KPRC and KPI is domestic prices of South Korea. However, there was no issue regarding the quality of the provided information because KPRC and KPI data were authorized by the Ministry of Strategy and Finance of Korea.

Figures for bentonite were limited from 2004 to 2015 as data was unavailable for the years before 2004. Prices were retrieved from half-yearly data. The cost information extracted from The Information on Commodity Prices and Price Information of Korea was converted to USD (exchange rate: end of November 2015).

Table 3 shows the characteristics of the collected data.

Tunnel excavation and disposal hole cost of 2015 increased by $138 \%$ compared to 2000 while bentonite and backfilling cost showed a relatively small increase of $27 \%$. The disposal hole excavation cost would be almost 25 times more expensive than the tunnel excavation cost. Because disposal hole excavation does not excavate by the blasting technique that is used in regular construction work. Instead, it uses equipment, such as the TBM (Tunnel Boring Machine), to excavate the disposal hole precisely [6]. The bentonite price used in the present study was $551.78 \mathrm{USD} /$ ton. The bentonite price for general purpose was about from 100 to $220 \mathrm{USD} /$ ton in South Korea $[22,23]$. However, the bentonite for a disposal facility needs the highest quality. Consequently, there is a considerable price difference between general purpose structures and disposal facilities. 
TABLE 3: Characteristics of the collected data.

\begin{tabular}{|c|c|c|c|c|c|c|}
\hline \multirow{2}{*}{ Cost driver } & & \multicolumn{3}{|c|}{ Price volatility } & \multirow{2}{*}{ Collection period } & \multirow{2}{*}{ Data types } \\
\hline & & $2000(2004)$ & 2015 & Growth rate & & \\
\hline $\begin{array}{l}\text { Tunnel excavation } \\
{\left[\mathrm{USD} / \mathrm{m}^{3}\right]}\end{array}$ & & 22.74 & 54.18 & $138 \%$ & 2000-2015 & Half-yearly \\
\hline $\begin{array}{l}\text { Disposal hole } \\
{\left[\mathrm{USD} / \mathrm{m}^{3}\right]}\end{array}$ & & 561.45 & $1,337.62$ & $138 \%$ & 2000-2015 & Half-yearly \\
\hline $\begin{array}{l}\text { Bentonite } \\
\text { [USD/ton] }\end{array}$ & & 432.94 & 551.78 & $27 \%$ & 2004-2015 & Half-yearly \\
\hline \multirow{3}{*}{$\begin{array}{l}\text { Canister } \\
{[\mathrm{USD} / \mathrm{kg}]}\end{array}$} & Cast iron & 1.44 & 2.55 & $76 \%$ & 2000-2015 & Half-yearly \\
\hline & Copper plate & 3.48 & 7.31 & $110 \%$ & $2000-2015$ & Half-yearly \\
\hline & Copper powder & 22.07 & 45.84 & $108 \%$ & 2000-2015 & Half-yearly \\
\hline $\begin{array}{l}\text { Backfilling } \\
\text { [USD/kg] }\end{array}$ & & 148.44 & 189.18 & $27 \%$ & 2004-2015 & Half-yearly \\
\hline
\end{tabular}

TABLE 4: The cost analysis results of four disposal alternatives (unit: USD/bundle).

\begin{tabular}{lccccccc}
\hline & \multirow{2}{*}{ Tunnel excavation } & Disposal hole & Bentonite & \multicolumn{2}{c}{ Canister } & \multirow{2}{*}{ Backfilling } & \multirow{2}{*}{ Unit cost per bundle } \\
& & & & & Cast iron & Copper & \\
KRS-1 & 20.94 & 138.99 & 79.37 & 135.87 & 177.93 & 73.10 & 626.20 \\
A-KRS-1 & 14.80 & 83.95 & 55.24 & 51.24 & 199.73 & 51.69 & 456.65 \\
A-KRS-21 & 8.02 & 75.52 & 45.52 & 79.10 & 235.74 & 28.00 & 471.90 \\
A-KRS-22 & 8.02 & 75.52 & 42.05 & 79.10 & 235.74 & 28.00 & 468.43 \\
\hline
\end{tabular}

\section{Results}

3.1. The Cost Estimation and Efficiency Analysis of Disposal Alternatives for the 2015 Price. Table 4 shows the results of the unit cost per bundle for disposal alternatives.

The price per bundle is 626.20 USD for KRS-1, 456.65 USD for A-KRS-1, 471.90 USD for A-KRS-21, and 468.43 USD for A-KRS-22.

As can be seen from these results, A-KRS-1 is the most efficient in terms of price per bundle for 2015, followed by A-KRS-22, A-KRS-21, and KRS-1. A-KRS-1 differed from A-KRS-22, the second most efficient alternative, by 63.87 USD in the price of cast iron and copper. This is because the A-KRS-1 involved the least amount of cast iron and copper, which were dominant cost drivers among raw materials. However, the overall difference only amounts to 11.78 USD because of bentonite, backfilling, tunnel excavation, and other disposal hole costs per bundle.

Figure 2 shows the cost efficiency for disposal alternatives based on 2015 price. The cost efficiency was conducted based on KRS-1 cost. Assuming the cost of KRS1 to be $100 \%$, it was found that A-KRS-1 can save approximately $27.1 \%$, A-KRS-21 can save approximately $24.6 \%$, and A-KRS-22 can save approximately $25.2 \%$. It is shown that A-KRS-1 is approximately $1.9 \%$ more efficient than A-KRS-22.

3.2. Cost Estimation and Efficiency Analysis of Disposal Alternatives in Consideration of Future Price Volatility. Table 5 shows the results of the estimated ARIMA model. For all

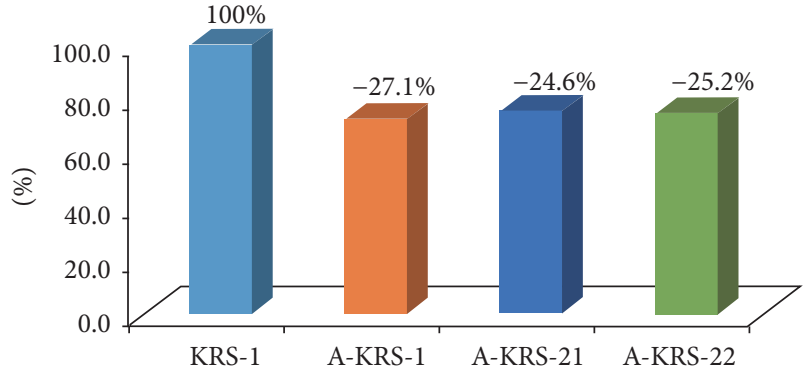

FIGURE 2: The cost efficiency of disposal alternatives-the price of 2015 year.

coefficients, except for cast iron, the forecasted values were significant at a 0.05 significance level. The significance level for cast iron at 0.059 was relatively unproblematic. The model was calculated once again by excluding the constant value. Also, the significant level of Ljung-Box $Q$ value, which was greater than 0.05 , is showing that the model conformity was acceptable.

Using the ARIMA forecasting model in Table 5 and data up to 2014 half-yearly to forecast costs for 2015, the results deviated from the actual by $-3.2 \%$ for tunnel excavation, $-3.2 \%$ for disposal hole, $0.1 \%$ for bentonite, $0 \%$ for cast iron, $-9.8 \%$ for copper plate, $2.9 \%$ for copper powder, and $0.1 \%$ for backfilling, all showing good forecasting power.

Table 6 shows the results of ARIMA analysis.

As can be seen in Table 6, the forecasting price for tunnel excavation in 2020 is 63.32 USD, with a UCL of 69.62 USD and LCL of 57.02 USD at $68 \%$ confidence interval. The forecasting price for copper plate with the highest volatility 
TABLE 5: ARIMA estimation models for the price forecasting of cost drivers.

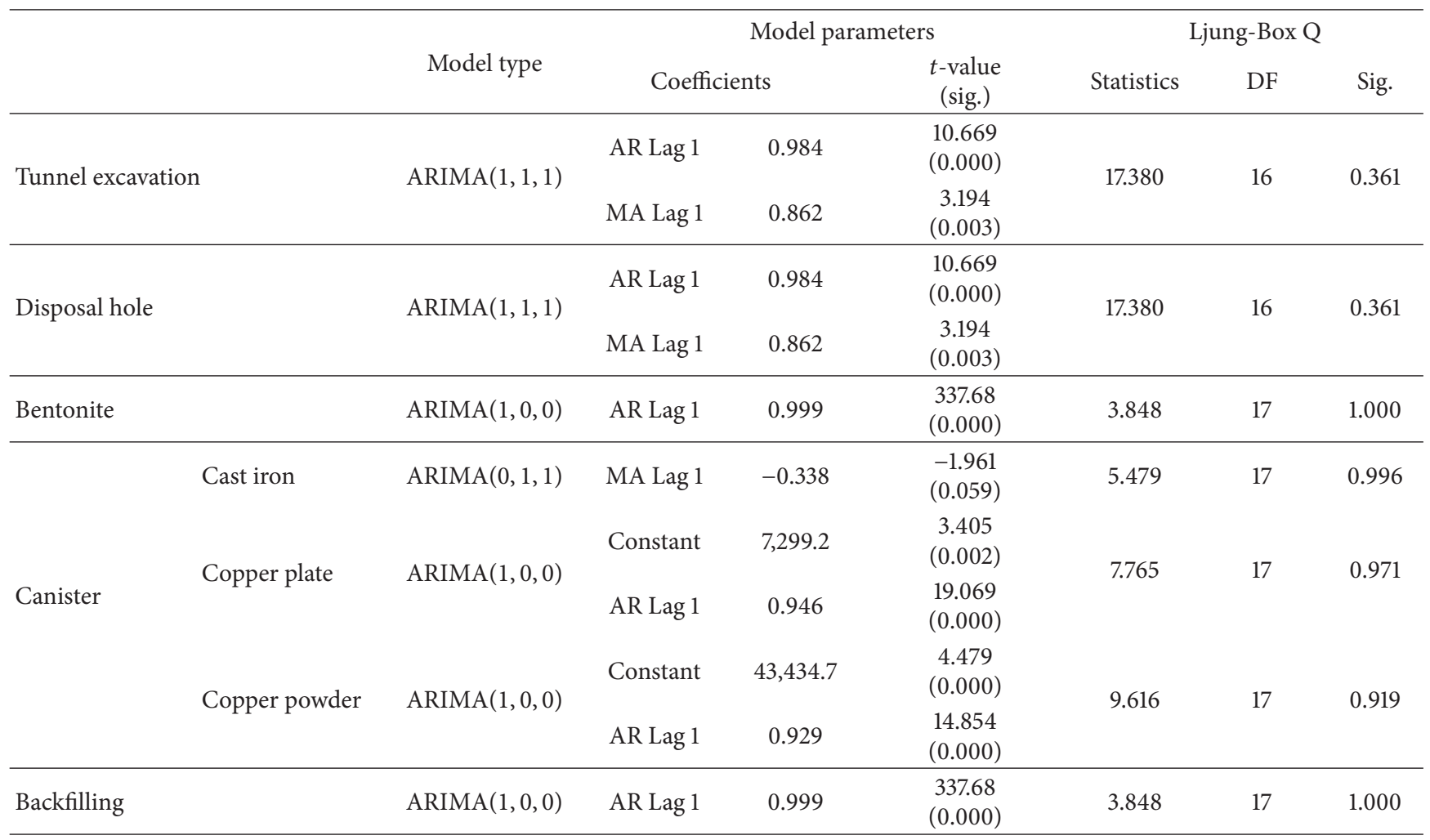

TABLE 6: The results of price forecasting at confidence interval 68\%-year 2020.

\begin{tabular}{|c|c|c|c|c|c|}
\hline & & \multicolumn{3}{|c|}{ CI (confidence interval) 68\% } & \multirow{2}{*}{ Fluctuation band (\%) } \\
\hline & & UCL & Forecasting & LCL & \\
\hline \multicolumn{2}{|c|}{ Tunnel excavation $\left[\mathrm{USD} / \mathrm{m}^{3}\right]$} & 69.62 & 63.32 & 57.02 & 9.9 \\
\hline \multicolumn{2}{|c|}{ Disposal hole $\left[\mathrm{USD} / \mathrm{m}^{3}\right]$} & $1,718.77$ & $1,563.28$ & $1,407.79$ & 9.9 \\
\hline \multicolumn{2}{|c|}{ Bentonite [USD/ton] } & 625.80 & 544.91 & 464.02 & 14.8 \\
\hline \multirow{3}{*}{$\begin{array}{l}\text { Canister } \\
{[\mathrm{USD} / \mathrm{kg}]}\end{array}$} & Cast iron & 3.03 & 2.55 & 2.06 & 18.8 \\
\hline & Copper plate & 8.86 & 6.84 & 4.81 & 29.5 \\
\hline & Copper powder & 51.56 & 41.16 & 30.76 & 25.3 \\
\hline \multicolumn{2}{|c|}{ Backfilling [USD/kg] } & 214.56 & 186.83 & 159.09 & 14.8 \\
\hline
\end{tabular}

is 6.84 USD, with a UCL of 8.86 USD and a LCL of 4.81 USD. The fluctuation band of the disposal tunnels and holes was the smallest, standing at $9.9 \%$, while that of the copper plate was the greatest at $29.5 \%$.

Figure 3 outlines the results of cost estimation results for the respective options by using the forecasted values from the ARIMA model. For KRS-1, a 2.14\% increase from 626.20 USD to 639.58 USD was observed. Decreases of $1.13 \%$ for A-KRS1, 2.38\% for A-KRS-21, and 2.39\% for A-KRS-22 were also observed. Such decreases in price, however little, were the result of price decreases expected for copper powder, copper plate, and bentonite, which backfilled in the ARIMA model.

Figure 4 compares the cost fluctuations of the disposal options using the ARIMA forecasting values with the cost volatility considering the $1.40 \%$ inflation. The analysis showed

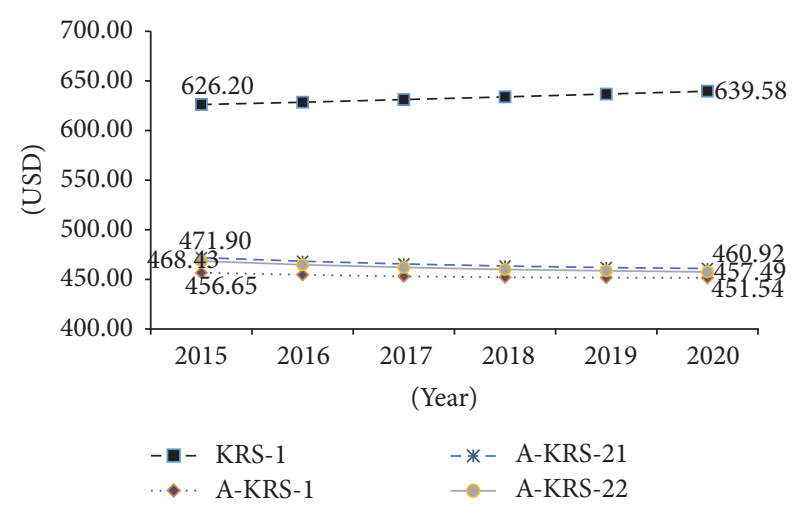

FIGURE 3: Cost estimation results of disposal alternatives using the ARIMA model. 
TABLE 7: The results of efficiency rank for 2020 at $68 \%$ confidence interval scenario.

\begin{tabular}{|c|c|c|c|c|c|c|c|c|}
\hline & & & Effici & ranl & scenario analysis $r$ & & & \\
\hline & & & & & & & Ran & \\
\hline & Number of cases & $\%$ & Number of cases & $\%$ & Number of cases & $\%$ & Number of cases & $\%$ \\
\hline KRS-1 & - & - & - & - & - & - & 243 & 100 \\
\hline A-KRS-1 & 174 & 72 & 27 & 11 & 42 & 17 & - & - \\
\hline A-KRS-21 & - & - & 42 & 17 & 201 & 83 & - & - \\
\hline A-KRS-22 & 69 & 28 & 174 & 72 & - & - & - & - \\
\hline Total & 243 & 100 & 243 & 100 & 243 & 100 & 243 & 100 \\
\hline
\end{tabular}

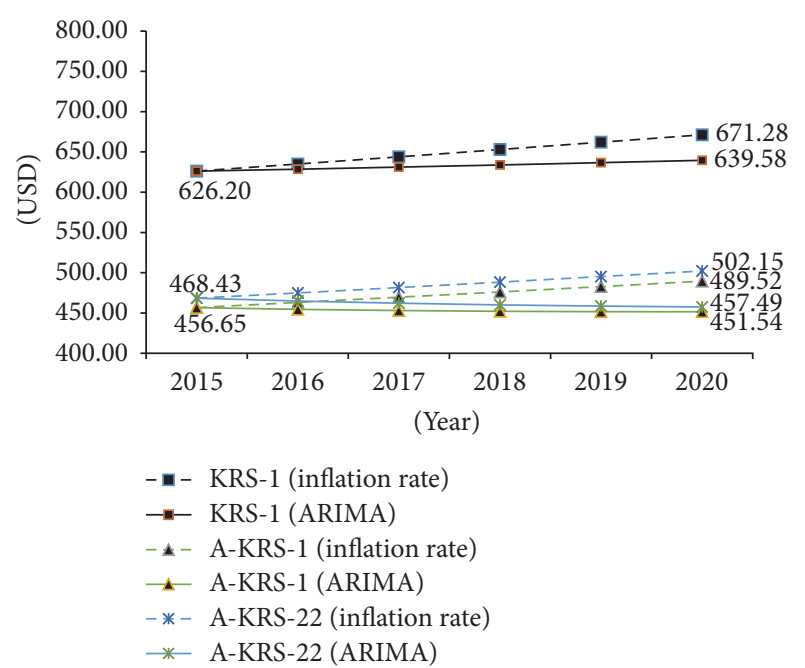

FIGURE 4: Cost estimation results of disposal alternatives using the ARIMA model and inflation rates.

that cost estimation using ARIMA differ from 2015 by $-2.335 \%$ to $2.136 \%$ while cost projections for 2020 , which take the inflation rates into consideration, were $7.199 \%$ higher than 2015 figures for all options, resulting in cost differences from the ARIMA model of up to $9.95 \%$. In sum, cost calculations using existing inflation rates resulted in higher estimated values than in the ARIMA model.

Figure 5 presents an analysis of cost efficiency for each option in different years using confidence intervals derived from the ARIMA model. KRS-1 had a maximum value of 755.54 USD and a minimum value of 523.59 USD in 2020, differing by $20.7 \%$ and $-16.4 \%$ from 2015 prices, respectively. These values were $16.9 \%$ and $-19.1 \%$ for A-KRS- 1 and $16.5 \%$ and $-21.2 \%$ for A-KRS- 22 .

As shown in Figure 5, an analysis using confidence intervals derived from the ARIMA model shows that the most efficient A-KRS-1 and the second most efficient A-KRS-22 overlap in many areas. In 2020, the lowest value for A-KRS-22 is 369.04 USD, which is lower than A-KRS-1's minimum value of 369.36 USD. This result demonstrates the volatility of costs for different scenarios, showing that the rankings of the cost efficiency can change, depending on the scenarios.

3.3. The Scenario Analysis Results of Disposal Alternatives. In this study, $243\left(3^{5}\right)$ scenarios are conducted for cost

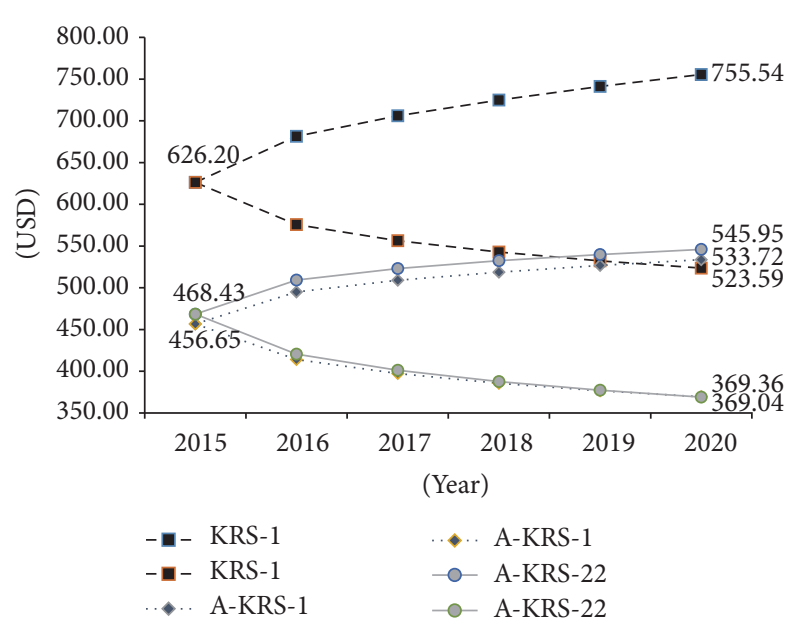

FIgURE 5: The cost fluctuation rang using confidence intervals derived from the ARIMA model.

efficiency analysis in consideration of price volatility because there are 5 cost drivers (tunnel excavation and disposal hole, bentonite and backfilling, cast iron, copper plate, and copper powder) and 3 kinds of price (UCL, forecasting, and LCL).

Table 7 shows the results of efficiency rank for 2020 at $68 \%$ confidence interval scenario. RANK 1 , the most efficient among the four alternatives, was comprised of A-KRS-1 at $72 \%$ and A-KRS- 22 at $28 \%$.

Table 8 shows the results of efficiency rank scores for each disposal alternative. A total of 243 scenarios, worth 100 points each, were analyzed. The most efficient alternative was awarded 40 points, followed by 30 for the second most efficient, 20 for the third most efficient, and 10 for the least efficient. A-KRS-1 earned 8,610 points for $35.4 \%$, while A-KRS-22 followed closely behind with 7,980 points for $32.9 \%$ among the total 24,300 points. These results are due to the narrowing of the score difference with the AKRS-1 method and the A-KRS-22 method taking up a large proportion in Rank 2 . The small difference indicates that the two alternatives may change in ranking if stability and volatility do not turn out as forecasted.

This reveals, probabilistically, which of the four disposal alternatives is the most efficient. If decisions based on current prices are made, there is only one possible option. In contrast, a variety of scenarios can be developed by considering future 
TABLE 8: The results of efficiency rank scores for all cases.

\begin{tabular}{|c|c|c|c|c|c|c|c|}
\hline & \multicolumn{4}{|c|}{ Scores of cases } & \multirow{2}{*}{ Total Score* } & \multirow{2}{*}{ Ratio (\%) } & \multirow{2}{*}{ Rank } \\
\hline & Rank 1 & Rank 2 & Rank 3 & Rank 4 & & & \\
\hline KRS-1 & - & - & - & 2,430 & 2,430 & 10.0 & 4 \\
\hline A-KRS-1 & 6,960 & 810 & 840 & - & 8,610 & 35.4 & 1 \\
\hline A-KRS-21 & - & 1,260 & 4,020 & - & 5,280 & 21.7 & 3 \\
\hline A-KRS-22 & 2,760 & 5,220 & - & - & 7,980 & 32.9 & 2 \\
\hline Total & 9,720 & 7,290 & 4,860 & 2,430 & 24,300 & 100 & \\
\hline
\end{tabular}

${ }^{*}$ Rank $1=40$ points, Rank $2=30$ points, Rank $3=20$ points, and Rank $4=10$ points.

volatility. This method provides results in terms of probability and degree of risks, thus allowing better decisions to be made by policymakers.

\section{Conclusions}

The objective of this study is to conduct cost efficiency analysis of the disposal alternatives in consideration of current price and price volatility for the construction cost of radioactive waste repository. To identify the disposal cost efficiency for the four disposal alternatives, comparative analysis of unit module was conducted.

The results of this study are as follows.

Firstly, A-KRS-1 is the most efficient in terms of price per bundle, followed by A-KRS-22, A-KRS-21, and KRS-1. This is because the A-KRS-1 involved the least amount of material cost of canister such as cast iron and copper, which were dominant cost drivers among raw materials. However, the overall difference only amounts to 11.78 USD because other costs of A-KRS-1 except material cost of canister are higher than A-KRS-22. This is a result showing that the positions of the two scenarios may change if, going forward, the price of disposition tunnels or bentonite increases while that of cast iron or copper drops.

Secondly, as for the results using ARIMA model, except in the case of KRS-1, the cost per bundle of A-KRS-1, A-KRS-21, and A-KRS-22 is decreased. Such decreases in price, however little, were the result of price decreases expected for copper powder, copper plate, and bentonite, which backfilled in the ARIMA model.

Thirdly, cost estimates using ARIMA show little change or decreases in cost while cost projections using inflation rates for 2020 resulted in approximately $7.2 \%$ increases compared to 2015 for all options. In sum, cost calculations using existing inflation rates resulted in higher estimated values than in the ARIMA model.

Lastly, as for the results of scenario analysis, A-KRS-1 earned 8,610 points, while A-KRS-22 followed closely behind with 7,980 points among the total 24,300 points. These results are due to the narrowing of the score difference with the A-KRS-1 method and the A-KRS-22 method taking up a large proportion in Rank 2. The small difference indicates that the two alternatives may change in ranking if stability and volatility do not turn out as forecasted. This reveals, probabilistically, which of the four disposal alternatives is the most efficient. If decisions based on current prices are made, there is only one possible option. In contrast, a variety of scenarios can be developed by considering future volatility. This scenario method provides results in terms of probability and degree of risks, thus allowing better decisions to be made by policymakers.

Taking into consideration the fact that very few previous studies regarding disposal alternatives have been conducted, the results of this study provide invaluable policy data for any nation considering the construction of spent nuclear fuel repository.

\section{Competing Interests}

The authors declare that they have no competing interests.

\section{Acknowledgments}

This work was supported by the National Research Foundation of Korea Grant funded by the Korean Government (NRF-2014S1A5B5A07042603).

\section{References}

[1] Korea Atomic Industrial Forum, Nuclear Energy Yearbook, KAIF Press, Seoul, South Korea, 2012.

[2] National Assembly Budget Office, Issues and Problems of Nuclear Power Generation Costs, National Assembly Budget Office, Seoul, South Korea, 2014.

[3] Korea Hydro \& Nuclear Power Co. LTD, Gyeongju, Korea, 2016, http://www.khnp.co.kr.

[4] S. Kim, W. Ko, and S. Bang, "Analysis of unit process cost for an engineering-scale pyroprocess facility using a process costing method in Korea," Energies, vol. 8, no. 8, pp. 8775-8797, 2015.

[5] S. K. Kim, M. S. Lee, H. J. Choi et al., "The role of pyroprocessing in decreasing disposal cost in Korea," Progress in Nuclear Energy, vol. 56, pp. 7-14, 2012.

[6] S. K. Kim, M. S. Lee, W. I. Ko, Y. Chung, and S. Bang, "Cost efficiency analysis of disposal alternatives in Korea," Progress in Nuclear Energy, vol. 53, no. 6, pp. 722-728, 2011.

[7] D.-K. Cho, Y. Lee, J.-Y. Lee, and J. Choi, "Characteristics of a geological disposal system for the increasing burn-up of spent nuclear fuel in Korea," Journal of Nuclear Science and Technology, vol. 44, no. 10, pp. 1306-1316, 2007.

[8] S. K. Kim and J. W. Choi, "Assessment of the cost of underground facilities of a high-level waste repository in Korea," Nuclear Engineering and Technology, vol. 38, no. 6, pp. 561-574, 2006. 
[9] J. Lee, D. Cho, H. Choi, and J. Choi, "Concept of a Korean reference disposal system for spent fuels," Journal of Nuclear Science and Technology, vol. 44, no. 12, pp. 1565-1573, 2007.

[10] S. K. Kim, M. S. Lee, H. J. Choi, J. W. Choi, and S. T. Revankar, "Availability of a probabilistic cost estimation for the price effect of Cu powder and bentonite on an HLW disposal cost in Korea," Progress in Nuclear Energy, vol. 51, no. 6, pp. 649-657, 2009.

[11] Notification No. 2015-132, Regulations for Calculating Radioactive Waste Management Costs and Spent Fuel Management Charges, Ministry of Trade, Industry and Energy, Sejong, Korea, 2015.

[12] T. Saanio and M. Kokko, KRS-1 Cost Estimation for the Underground Facilities of Korean Reference HLW Disposal System, 2007.

[13] S. Kim, W. Ko, and S. Bang, "Assessment of activity-based pyroprocess costs for an engineering-scale facility in Korea," Nuclear Engineering and Technology, vol. 47, no. 7, pp. 849-858, 2015.

[14] T. Y. Baek, Cost \& Management Accounting, Shinyoungsa Press, Seoul, South Korea, 2012.

[15] M. M. Mowen, D. R. Hansen, and D. L. Heitger, Cornerstones of Managerial Accounting, Cengage Learning, Boston, Mass, USA, 2014.

[16] S. K. Kim, K. S. Chun, H. J. Choi, J. W. Choi, and T.-W. Kwak, "Cost estimation of the canisters for an HLW repository in Korea," Progress in Nuclear Energy, vol. 49, no. 7, pp. 555-566, 2007.

[17] G. E. Box and G. M. Jenkins, Times series analysis. Forecasting and control, Holden-Day, San Francisco, California, USA, 5th edition, 1970 .

[18] D. B. Jeong, Demand Forecasting of Time Series I, Hannarae Publishing, Seoul, South Korea, 2009.

[19] H. J. No, Well-Defined Time Series Analysis utilizing SPSS/Excel, YSWPUB, Paju, Korea, 2010.

[20] W. H. Greene, Econometric Analysis, Pearson Education, New Jersey, NJ, USA, 2003.

[21] Korea Specialty Contractors Association, Construction Industry Wages Survey Report, Korea Specialty Contractors Association, Seoul, Republic of Korea, 2000.

[22] Korea Price Research Center Corp, The Information on Commodity Prices, KPRC Press, Seoul, South Korea, 2000-2015.

[23] Korea Price Information Corporation, "Price Information of Korea," KPI Press, Seoul, Republic of Korea, 2000-2015. 

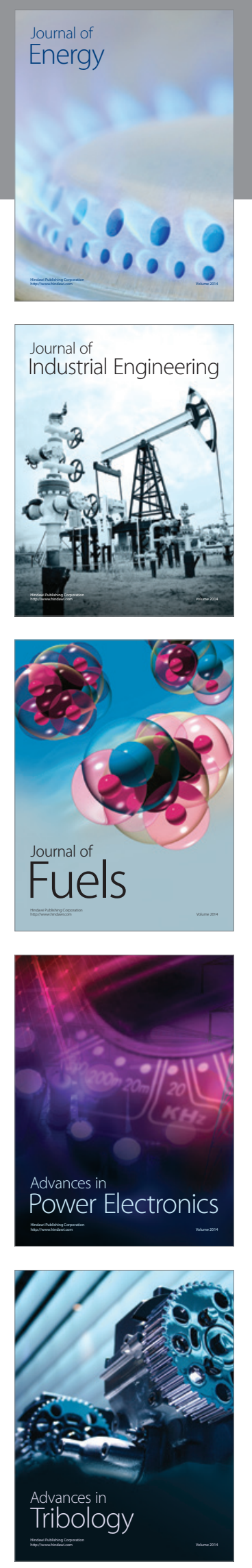
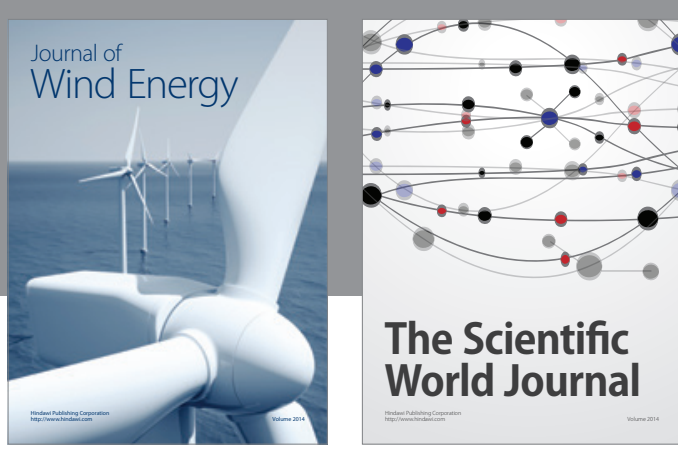

The Scientific World Journal
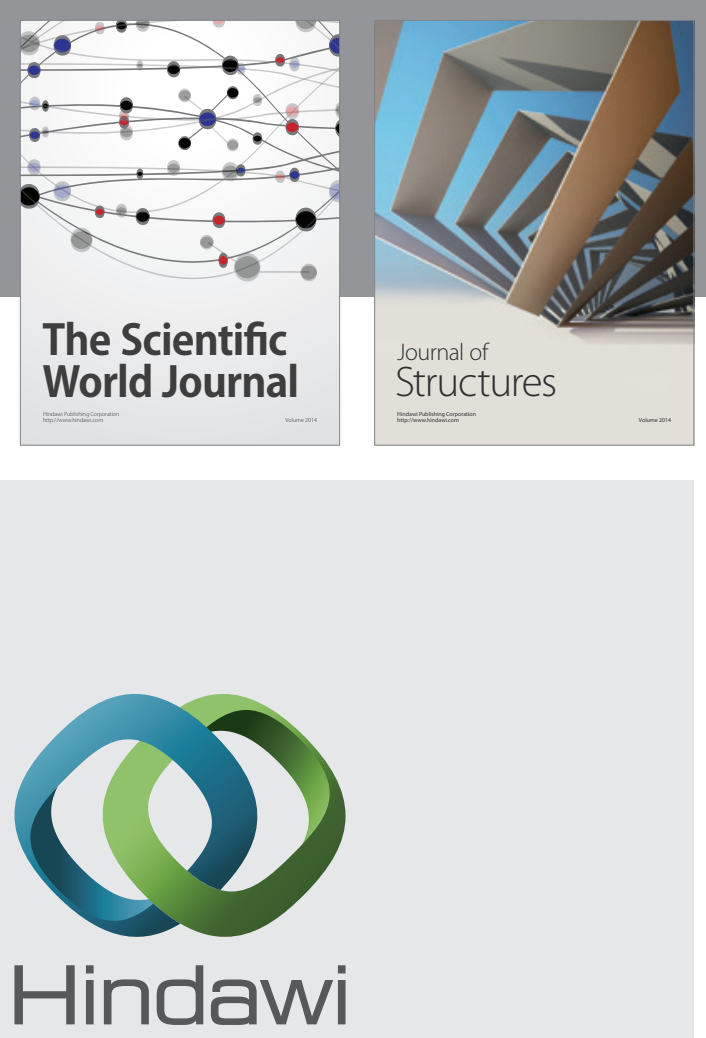

Submit your manuscripts at

http://www.hindawi.com
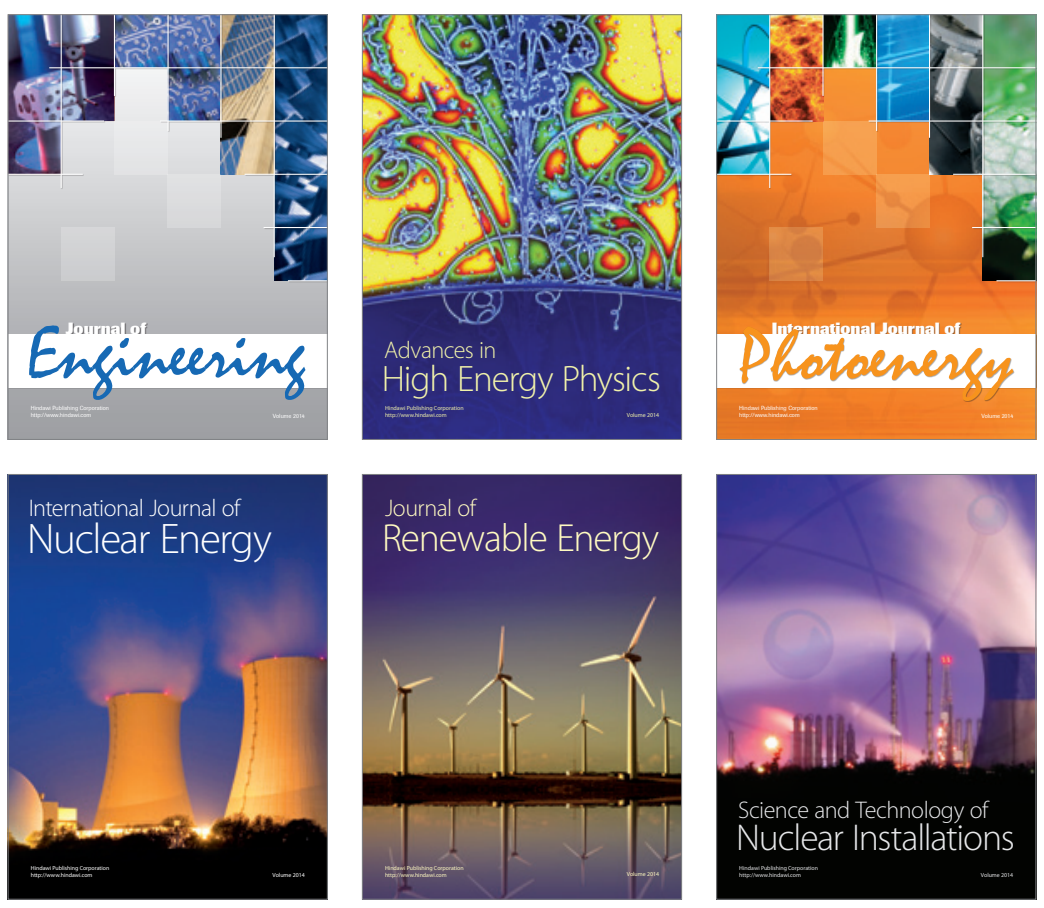
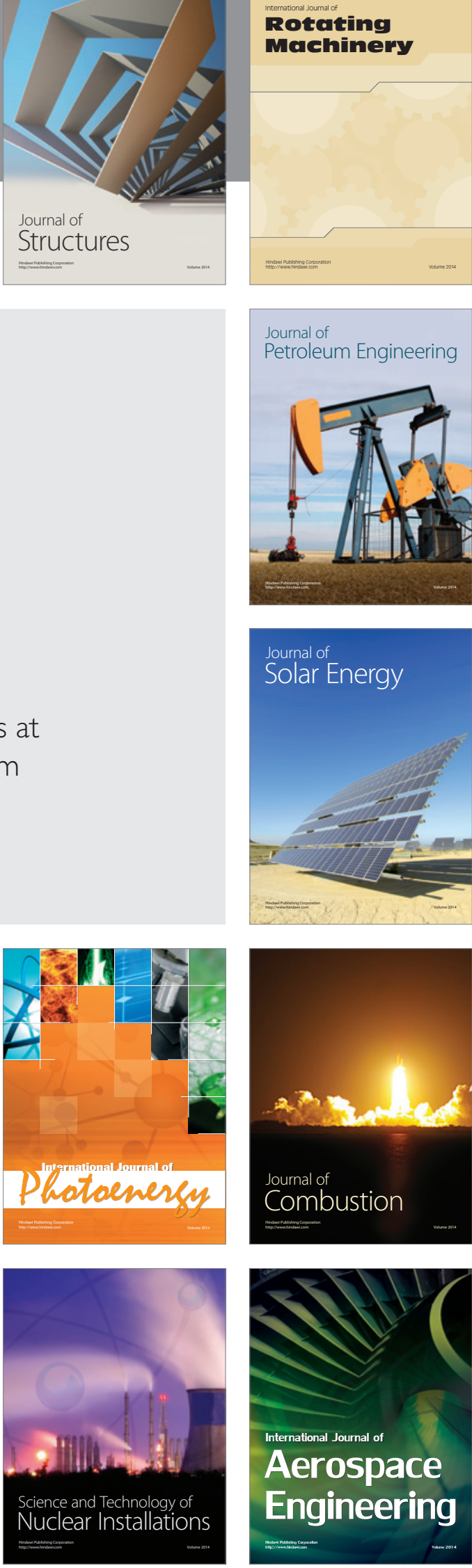